\title{
Microbiological and molecular impacts of AbiK on the lytic cycle of Lactococcus lactis phages of the 936 and P335 species
}

\author{
Isabelle Boucher, ${ }^{1}$ Éric Émond, ${ }^{1}+$ Éric Dion, ${ }^{1}$ Diane Montpetit ${ }^{2}$ \\ and Sylvain Moineau ${ }^{1}$
}

Author for correspondence: Sylvain Moineau. Tel: +1 418656 3712. Fax: +1 4186562861.

e-mail: Sylvain.Moineau@bcm.ulaval.ca

\footnotetext{
1 Department of Biochemistry and Microbiology, Faculté des Sciences et de Génie, Groupe de Recherche en Écologie Buccale (GREB), Faculté de Médecine Dentaire, Université Laval, Québec, Canada G1K 7P4

2 Agriculture and Agri-Food Canada, Food Research and Development Centre (FRDC), 3600 Casavant Blvd, St-Hyacinthe, Québec, Canada J2S 8E3
}

\begin{abstract}
The lactococcal abortive infection mechanism AbiK was previously shown to be highly effective against the small isometric-headed bacteriophage ul36 of the P335 species, as evidenced by an efficiency of plaquing (e.o.p.) of $10^{-6}$, a 14fold reduction in the burst size and an efficiency at which centres of infection form (e.c.o.i.) of $0.5 \%$. No phage DNA was detected in the infected AbiK ${ }^{+}$cells [Émond, É., Holler, B. J., Boucher, I., Vandenbergh, P. A., Vedamuthu, E. R., Kondo, J. K. \& Moineau, S. (1997). Appl Environ Microbiol 63, 1274-1283]. Here, the effects of AbiK are compared on the small isometric-headed phages $\mathrm{p2}$ and P008 (936 species) and on the phage P335 (P335 species). The microbiological impacts of AbiK on $p 2$ were relatively similar to those reported for ul36, with an e.o.p. of $\mathbf{1 0}^{-6}$, an 11-fold reduction in the burst size and an e.c.o.i. of $5 \%$. Contrary to phage ul36, replication of phage p2 DNA was observed in the $\mathrm{AbiK}^{+}$cells. Only immature forms (concatemeric and circular DNA) of phage p2 DNA were found, indicating that the presence of AbiK prevented phage DNA maturation. These distinct molecular consequences of AbiK were also observed for phages P335 and P008, two phages that propagate on the same host. To the knowledge of the authors, this is the first time that different phage responses towards an Abi system have been reported.
\end{abstract}

Keywords: bacteriophages, abortive infection mechanism, Lactococcus

\section{INTRODUCTION}

Lactococcus lactis is a Gram-positive lactic acid bacterium used to manufacture fermented dairy products such as sour cream, buttermilk and cheeses. The acidification process in large-scale milk fermentation can be delayed due to lytic phages present in pasteurized milk and in the manufacturing environment (Dinsmore \& Klaenhammer, 1995). Lactococcal phages are classified into 12 genetically distinct groups (Jarvis et al., 1991), but only three of them (936, P335 and c2 species) are repeatedly isolated in dairy plants worldwide (Moineau et al., 1992, 1996). The three species are members of the Siphoviridae family (with a non-

\footnotetext{
† Present address: Department of Food Science and Nutrition and Centre de Recherche en Science et Technologie du Lait (STELA), Faculté des Sciences de l'Agriculture et de l'Alimentation, Université Laval, Québec, Canada G1K 7P4.

Abbreviations: c.o.i., centres of infection; e.c.o.i., efficiency at which centres of infection form; e.o.p., efficiency of plaquing.
}

contractile tail), which also includes the coliphage lambda (Pringle, 1996). Phages of the 936 and P335 species have small isometric heads, whereas the c2-like phages have a prolate head. Many bacterial strains carrying defence systems against these phages have been identified (Allison \& Klaenhammer, 1998).

Abortive infection mechanisms (Abi) form a particular class of natural anti-phage systems. These phage resistance mechanisms are generally plasmid-encoded and act after phage adsorption, DNA penetration and early gene expression. Their intracellular activities result in reduced burst size, efficiency of plaquing (e.o.p.) and efficiency at which centres of infection form (e.c.o.i.). One of the distinctive aspects of Abi systems is the massive cellular death observed in infected cells (Durmaz et al., 1992; Geis et al., 1992; Sing \& Klaenhammer, 1990). To date, 17 Abi systems have been cloned and sequenced in L. lactis.

The first lactococcal Abi system, AbiA, was isolated (Klaenhammer \& Sanozky, 1985) from the highly 
resistant industrial strain L. lactis ME2 (Klaenhammer, 1989; Hill et al., 1990). In P335-infected $\mathrm{AbiA}^{+}$cells, phage DNA replication and major capsid protein production are absent (Hill et al., 1991; Moineau et al., 1993). Site-directed mutagenesis of a leucine repeat motif in AbiA showed that this structure is essential to the phage resistance phenotype (Dinsmore et al., 1998). A specific DNA fragment isolated from a mutant phage, insensitive to AbiA, reduced the resistance phenotype towards the wild-type phage when provided in trans in the $\mathrm{Abi}^{+}$cells (Dinsmore \& Klaenhammer, 1997). A similar phenomenon was observed for AbiD1 (Bidnenko et al., 1995), which contains two helix-turn-helix motifs in its sequence (Anba et al., 1995). A helix-turn-helix motif was also identified at the N-terminal end of AbiJ (Deng et al., 1997). Amino acid motifs characteristic of DNA-binding functions were not detected in AbiD and AbiF. However, homologies were found between AbiD1 and $\mathrm{AbiF}$ (47\% identity), between $\mathrm{AbiD}$ and $\mathrm{AbiD} 1$ (28\% identity), and between AbiD and AbiF (26\% identity) (Garvey et al., 1995; McLandsborough et al., 1995).

The genetic determinants of AbiB (Cluzel et al., 1991), AbiH (Prévots et al., 1996) and AbiN (Prévots et al., 1998) are encoded on the chromosome. The action of $\mathrm{AbiB}$ is possibly induced by an early phage transcript and leads to the degradation of phage mRNAs 1015 min after infection (Parreira et al., 1996). For AbiE (Garvey et al., 1995), AbiG (O'Connor et al., 1996) and AbiL (Deng et al., 1999), a DNA region containing two ORFs is associated with the phage resistance phenotype. The requirement of the two peptides to generate full resistance has yet to be established in the case of AbiE. Two putative integral membrane-spanning helices were identified near the N-terminal end of AbiC (Durmaz et al., 1992). This system caused a reduction in the synthesis of the major capsid protein of a P335 phage (Moineau et al., 1993). The AbiQ mechanism appears to result in defective assembly of 936 and c2 phages (Emond et al., 1998). Three other Abi genes were also sequenced, namely, AbiI (Su et al., 1997), AbiO (Prévots \& Ritzenthaler, 1998) and AbiP (GenGank accession no. U90222).

In a previous study, we showed that plasmid pSRQ800 coded for the phage abortive infection system AbiK and conferred strong resistance against small isometric phages of the 936 and P335 species (Emond et al., 1997). A database query, based on amino acid composition, suggested that AbiK and AbiA might be in the same protein family. Furthermore, as with AbiA, replication of phage ul36 (P335 species) DNA and production of its major capsid protein were not observed in the $\mathrm{AbiK}^{+}$. infected cells (Emond et al., 1997). The characterization of Abi systems is generally perfomed using only one phage species and it is generally assumed that the observations will be similar towards the other phage species. Here, we report distinct observations on the lytic cycle of 936 and P335 phages resulting from the presence of AbiK.

\section{METHODS}

Bacterial strains, phages and media. The bacterial strains and phages used in this study are listed in Table 1. Lactococcus strains were grown at $30{ }^{\circ} \mathrm{C}$ in $\mathrm{M} 17$ broth containing $0.5 \%$ glucose (GM17) and supplemented, when required, with $5 \mu \mathrm{g}$ erythromycin or chloramphenicol $\mathrm{ml}^{-1}$.

Bacteriophage propagation and assays. High phage titre was obtained by the method of Jarvis (1978). Phage p2K, a variant of phage p2, was isolated from a single plaque (Moineau et al., 1994) obtained by infecting $\mathrm{AbiK}^{+}$cells with a m.o.i. of 5 . e.o.p. was assessed as described by Sanders \& Klaenhammer (1980). One-step growth curves and centres of infection (c.o.i.) were assayed as described previously (Moineau et al., 1993). The phage burst size was estimated as the ratio between the phage titre at two consecutive latent phases on the growth curves. The e.c.o.i. was calculated by dividing the number of c.o.i. on the resistant strain by the number of c.o.i. on the sensitive strain $\times 100$. In coinfection assays, phages $\mathrm{p} 2$ and $\mathrm{p} 2 \mathrm{k}$ were simultaneously added at a m.o.i. of 1 .

DNA isolation and manipulation. Routine DNA manipulations were carried out as described by Sambrook et al. (1989). Phage DNA was isolated according to the method of Chibani Azaïez et al. (1998) with the following modifications: concentrated phages were treated with proteinase $\mathrm{K}(1 \mathrm{mg}$ $\left.\mathrm{ml}^{-1}\right)$ for $1 \mathrm{~h}$ at $37^{\circ} \mathrm{C}$. Phenol/chloroform $(24: 1, \mathrm{v} / \mathrm{v})$ extractions were repeated until a white interface was absent. DNA was precipitated using 2 vols ethanol and dissolved in $50 \mu \mathrm{l}$ ${ }^{2} \mathrm{H}_{2} \mathrm{O}$. Purified DNA was digested with restriction enzymes as recommended by the manufacturer (Boehringer Mannheim).

Phage p2 restriction map. Phage p2 DNA was digested with the restriction enzymes EcoRI, EcoRV, HindIII, NcoI, SalI, ScaI and SphI in single and double digestions. Restriction fragments were separated by electrophoresis on agarose gel, stained with ethidium bromide and photographed under UV illumination. The profiles were used to establish the EcoRV restriction map.

Phage DNA replication. Intracellular phage DNA replication was monitored by the method of Hill et al. (1991). In short, total DNA was isolated from cultures infected at a m.o.i. of 1, digested with $E c o R V$ and heated at $65^{\circ} \mathrm{C}$ for $10 \mathrm{~min}$. The heat treatment prior to migration on gel allowed the identification of the fragments carrying the cos sites. The fragments were then electrophoretically separated on a $0.8 \%$ agarose gel. After ethidium bromide staining, DNA was visualized under UV and photographed. For phage p2, DNA was transferred to Hybond-N nylon membranes (Amersham) by capillary blotting (Southern, 1975). A probe was prepared by labelling the EcoRV fragments from the phage p2 genome with the DIGHigh Prime Kit (Boehringer Mannheim). Prehybridization, hybridization and posthybridization washes as well as detection were performed as directed by the manufacturer. The standard hybridization buffer (50\% formamide) and CSPD were used for the hybridization steps and chemiluminescent detection, respectively.

Electron microscopy. Phage morphology was observed as described previously (Moineau et al., 1992). The lytic cycle was monitored by electron microscopy according to the following protocol. The sensitive and resistant hosts were grown in GM17 to an optical density of 0.5. Calcium chloride 
Table 1. Bacterial strains, bacteriophages and plasmids used in this study

\begin{tabular}{|c|c|c|}
\hline $\begin{array}{l}\text { Bacterial strain, } \\
\text { bacteriophage } \\
\text { or plasmid }\end{array}$ & Relevant characteristics* & Source $†$ \\
\hline \multicolumn{3}{|c|}{ L. lactis subsp. cremoris } \\
\hline LM0230 & Plasmid-free, host for phage $\mathrm{p} 2$ & McKay et al. (1972) \\
\hline SMQ-16 & LM0230(pSA3), $\mathrm{Tc}^{\mathrm{r}} \mathrm{Em}^{\mathrm{r}}$ & Moineau et al. (1995) \\
\hline SMQ-38 & LM0230(pSRQ802), $\mathrm{Tc}^{\mathrm{r}} \mathrm{Em}^{\mathrm{r}} \mathrm{AbiK}^{+}$ & Émond et al. (1997) \\
\hline \multicolumn{3}{|c|}{ L. lactis subsp. lactis } \\
\hline $\mathrm{F} 4 / 2$ & Host for phages P008 and P335 & H. W. Ackermann ${ }^{1}$ \\
\hline SMQ-463 & F4/2(pSRQ817), $\mathrm{Cm}^{\mathrm{r}} \mathrm{AbiK}^{+}$ & This study \\
\hline SMQ-501 & $\mathrm{F} 4 / 2(\mathrm{pSRQ} 830), \mathrm{Cm}^{\mathrm{r}} \mathrm{AbiK}^{-}$ & This study \\
\hline \multicolumn{3}{|l|}{ Bacteriophages } \\
\hline $\mathrm{p} 2$ & 936 species, $\mathrm{AbiK}^{\mathrm{s}}$ & T. R. Klaenhammer ${ }^{2}$ \\
\hline $\mathrm{p} 2 \mathrm{~K}$ & 936 species, variant of phage $\mathrm{p} 2, \mathrm{AbiK}^{\mathrm{r}}$ & This study \\
\hline P008 & Type phage, 936 species, $\mathrm{AbiK}^{\mathrm{s}}$ & H. W. Ackermann ${ }^{1}$ \\
\hline P335 & Type phage, P335 species, $\mathrm{AbiK}^{\mathrm{s}}$ & T. R. Klaenhammer ${ }^{2}$ \\
\hline \multicolumn{3}{|l|}{ Plasmids } \\
\hline pSRQ802 & $\begin{array}{l}4.5 \mathrm{~kb} \text { EcoRI fragment from pSRQ800 cloned } \\
\text { into pSA3, } \mathrm{Tc}^{\mathrm{r}} \mathrm{Em}^{\mathrm{r}} \mathrm{AbiK}^{+}\end{array}$ & Émond et al. (1997) \\
\hline pSRQ817 & $\begin{array}{l}3 \cdot 8 \mathrm{~kb} \text { EcoRI-PvuII fragment from pSRQ800 } \\
\text { cloned into pMIG3, } \mathrm{Cm}^{\mathrm{r}} \mathrm{AbiK}^{+}\end{array}$ & Émond et al. (1997) \\
\hline pSRQ830 & $\begin{array}{l}\text { Frameshift mutation (BstEII/Klenow) of } a b i K \text { in } \\
\text { pSRQ } 817\end{array}$ & This study \\
\hline
\end{tabular}

*Tc, tetracycline; Em, erythromycin; Cm, chloramphenicol; AbiK, abortive infection mechanism. † 1, Félix-d'Hérelle Reference Center for Bacterial Viruses, Université Laval, Québec, Canada ; 2, North Carolina State University, Raleigh, NC, USA.

was then added at a final concentration of $10 \mathrm{mM}$, followed by phage p2 at a m.o.i. of 1 . The infected cells were incubated at $30^{\circ} \mathrm{C}$. At various time points, $1.7 \mathrm{ml}$ culture was transferred to an Eppendorf tube and cells were fixed using a modification of the method of Strausbauch et al. (1985). The cell pellets were resuspended in a glutaraldehyde solution $(2 \%$ in $0 \cdot 1 \mathrm{M}$ sodium cacodylate, $\mathrm{pH} 7 \cdot 3$ ) and incubated at room temperature for $1.5 \mathrm{~h}$. The cells were centrifuged and the pellets were embedded in $3 \%$ agar dissolved in $0 \cdot 1 \mathrm{M}$ sodium cacodylate. After gelification on ice, samples were cut into $0.5-1.0 \mathrm{~mm}^{3}$ pieces with a razor blade, rinsed five times in cacodylate buffer and post-fixed in $1 \% \mathrm{OsO}_{4}$ in water for $1.5 \mathrm{~h}$ at room temperature. The samples were rinsed in water, gradually dehydrated in increasing concentrations of ethanol solutions $(10-100 \%)$ and embedded in Spurr resin. After sectioning, the specimens were observed with a transmission electron microscope Phillips 420 at $80 \mathrm{kV}$.

\section{RESULTS}

\section{Effects of AbiK on phage development}

Three parameters (e.o.p., e.c.o.i. and burst size) were used to evaluate the effectiveness of this anti-phage system on the lactococcal phage p2 of the 936 species (Table 2). AbiK had a strong inhibitory effect on the $\mathrm{p} 2$ lytic cycle as the values of all parameters tested were dramatically reduced. In the presence of this abortive infection mechanism, the release of progeny phages by
Table 2. Effects of AbiK on phage $\mathrm{p} 2$ and $\mathrm{p} 2 \mathrm{~K}$ development

\begin{tabular}{|c|c|c|c|c|}
\hline \multirow[t]{2}{*}{ Assay } & \multicolumn{2}{|c|}{$\begin{array}{l}\mathrm{AbiK}^{-} \text {strain } \\
\text { SMQ-16 }\end{array}$} & \multicolumn{2}{|c|}{$\mathrm{AbiK}^{+}$strain $\mathrm{SMQ}-38$} \\
\hline & $\mathrm{p} 2$ & $\mathrm{p} 2 \mathrm{~K}$ & $\mathrm{p} 2$ & $\mathrm{p} 2 \mathrm{~K}$ \\
\hline e.o.p.* & 1 & 1 & $1 \cdot 3 \pm 0 \cdot 5 \times 10^{-6}$ & $0 \cdot 5 \pm 0 \cdot 1$ \\
\hline e.c.o.i. $(\%) \dagger$ & 100 & 100 & $4 \cdot 8 \pm 1 \cdot 3$ & $35 \cdot 2 \pm 2 \cdot 5$ \\
\hline Burst size* & $59 \cdot 3 \pm 12 \cdot 6$ & ND & $5 \cdot 1 \pm 1 \cdot 4$ & $44 \cdot 4 \pm 11 \cdot 4$ \\
\hline
\end{tabular}

ND, Not determined.

* Mean of three trials.

† Mean of at least four trials.

the infected cells (e.c.o.i.) was decreased 20-fold and the burst size was lowered more than 11-fold. These effects led to an e.o.p. of $10^{-6}$. A variant of phage $\mathrm{p} 2, \mathrm{p} 2 \mathrm{~K}$, which showed a strongly reduced sensitivity to AbiK was also isolated. Phage $\mathrm{p} 2 \mathrm{~K}$ had the same morphology and DNA restriction pattern as the wild-type phage $\mathrm{p} 2$ (data not shown). The e.o.p. and burst size of this mutant phage were similar to those of the wild-type phage on the sensitive strain SMQ-16 (Table 2). The release of progeny phages by the $\mathrm{AbiK}^{+}$strain was seven times greater for phage $\mathrm{p} 2 \mathrm{~K}$ than for $\mathrm{p} 2$. To determine if 
(a)

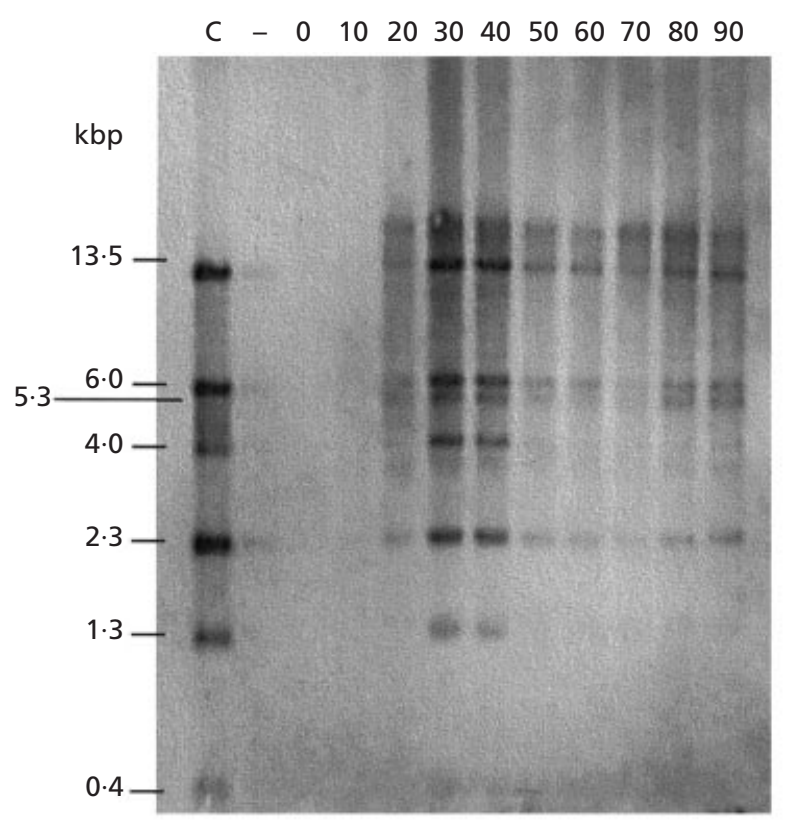

(b)

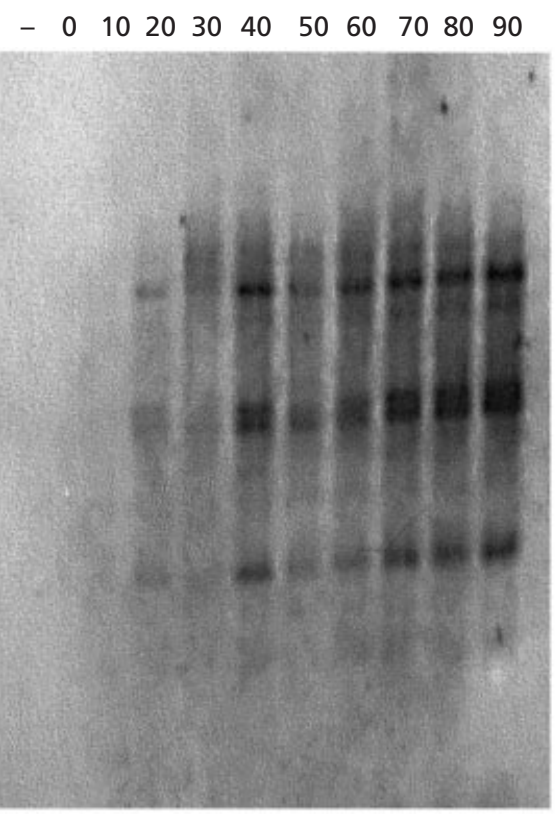

(c)

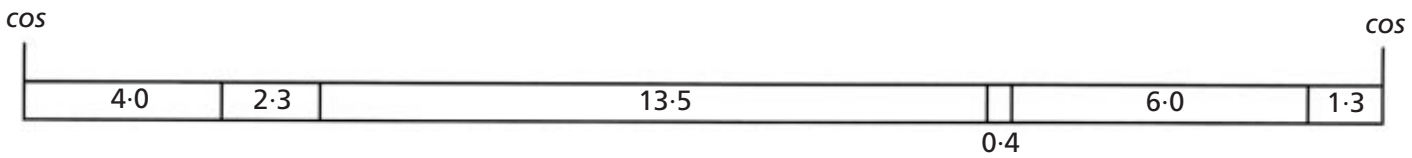

Fig. 1. DNA replication of phage $p 2$ in the absence or presence of AbiK. Phage p2 DNA replication was followed during the infection of L. lactis SMQ-16 (a) and SMQ-38 (b). Samples $(1 \mathrm{ml})$ of infected cultures (m.o.i. $=1)$ were taken every $10 \mathrm{~min}$ and total DNA was isolated from the cellular fraction by the method of Hill et al. (1991). DNA was digested with EcoRV, heat-treated $\left(65^{\circ} \mathrm{C}\right.$ for $\left.10 \mathrm{~min}\right)$ and restriction fragments were separated on a $0.8 \%$ agarose gel. Phage DNA was detected after Southern transfer using DIG-labelled EcoRV fragments of the phage genome. Numbers above the lanes indicate the time of sampling. C, phage p2 DNA digested with EcoRV and heat-treated; -, sample taken prior to infection. (c) EcoRV restriction map of p2.

the mutated allele in $\mathrm{p} 2 \mathrm{~K}$ was dominant or recessive, a coinfection assay was conducted. An e.c.o.i. of $23 \cdot 8 \pm 4 \cdot 1 \%$ was obtained when coinfecting an $\mathrm{Abi}^{+}$ strain with phages $\mathrm{p} 2$ and $\mathrm{p} 2 \mathrm{~K}$, as compared to e.c.o.i. values of $4.8 \pm 1.3 \%$ and $35.2 \pm 2.5 \%$ with single infections of $\mathrm{p} 2$ or $\mathrm{p} 2 \mathrm{~K}$, respectively. Therefore, these alleles are codominant.

\section{Phage $\mathrm{p} 2$ replication assay}

The restriction map of the cos-containing phage $\mathrm{p} 2$ genome was established. Only the positions of the EcoRV sites are indicated in Fig. 1(c). Phage DNA replication was temporally monitored in the infected $\mathrm{AbiK}^{-}$and $\mathrm{AbiK}^{+}$cells. The phage genome was rapidly replicated in the sensitive cells (Fig. 1a) as DNA appeared $20 \mathrm{~min}$ after infection, peaked at $30 \mathrm{~min}$ and then decreased after $40 \mathrm{~min}$. When the cells burst, they release progeny phages which are not recovered during the centrifugation step. This explains the reduction in the total amount of phage DNA at $40 \mathrm{~min}$ and beyond.
Cell lysis was also confirmed by a dramatic reduction in the optical density observed at $40 \mathrm{~min}$ (data not shown). The immature forms (circular and concatemer) of the phage genome with the cos sites covalently closed and the mature (linear single-length unit) form were simultaneously present in the sensitive cells. The immature form was associated with the presence of a $5.3 \mathrm{~kb}$ EcoRV restriction fragment corresponding to two smaller fragments of 1.3 and $4.0 \mathrm{~kb}$, joined by their cos termini (Fig. 1). In the $\mathrm{AbiK}^{+}$cells, phage p2 DNA also appeared $20 \mathrm{~min}$ post-infection and the amount of phage DNA increased continuously throughout the assay (Fig. 1b). No reduction in the optical density of the culture was observed (data not shown). Furthermore, only the immature forms of the phage genome were detected. These results indicated that phage p2 DNA replication did occur in the resistant cells and that the DNA was not processed to its mature form. These results are in contrast to a previous study where no phage ul36 DNA (P335 species) was detected in infected $\mathrm{AbiK}^{+}$cells (Émond et al., 1997). 
(a)

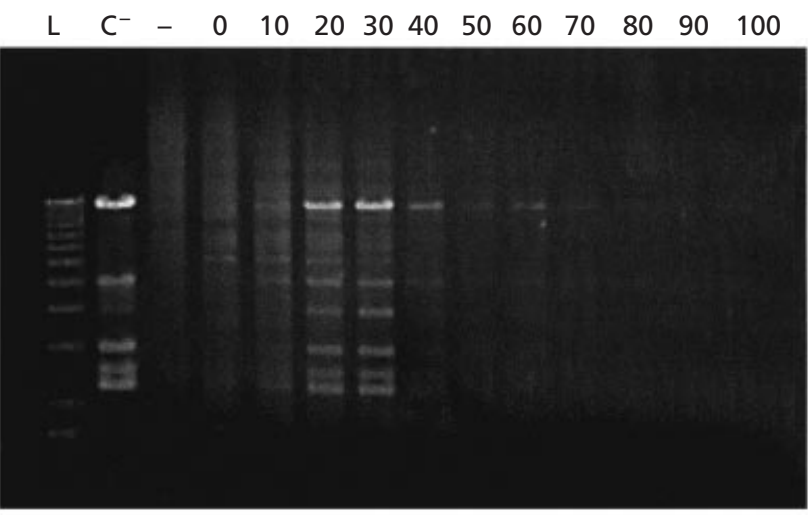

(c)
$\mathrm{L} \quad \mathrm{C}^{-}$
0
102030
$30 \quad 40$
$\begin{array}{llll}50 & 60 & 70 & 80\end{array}$
90100

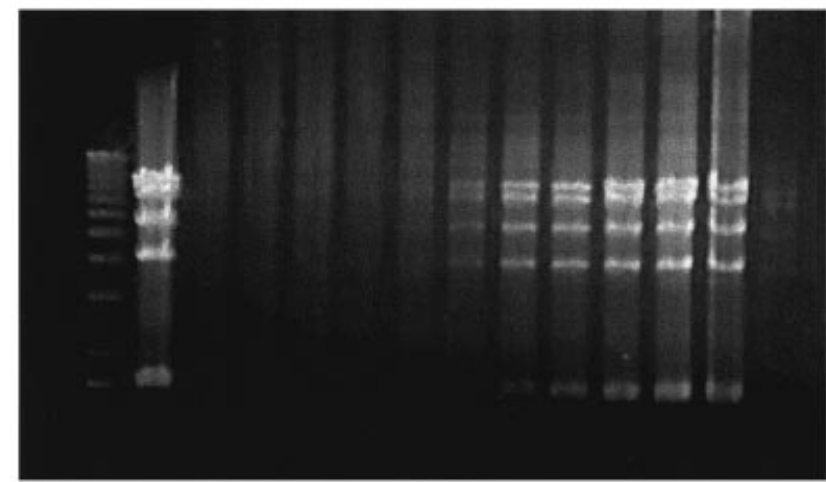

(b)

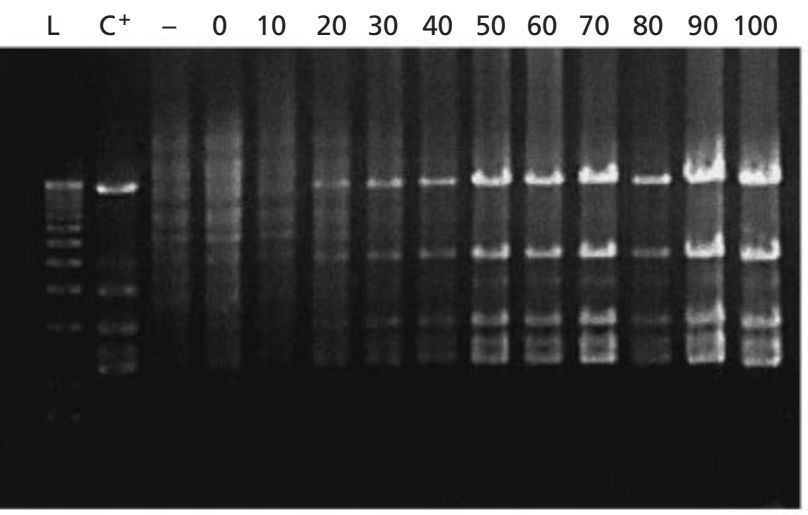

(d)
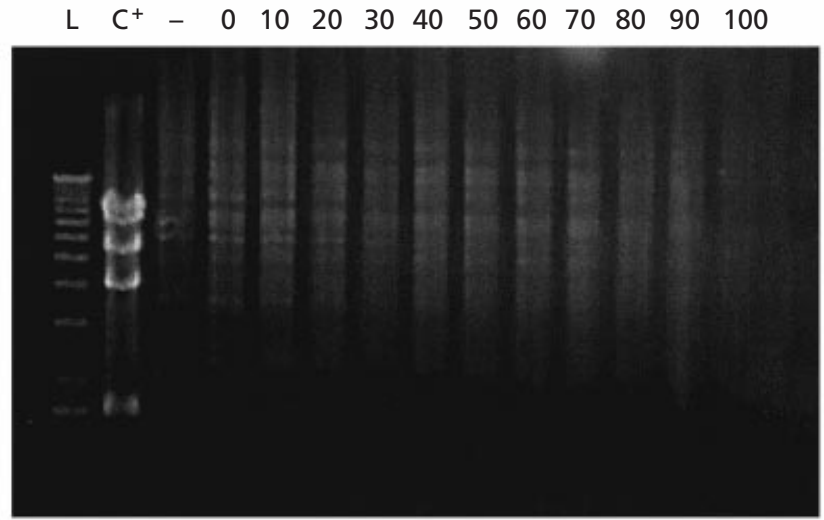

Fig. 2. DNA replication of phages $P 008$ and P335. Phage P008 DNA replication was followed during the infection of $L$. lactis F4/2 (a) and SMQ-463 (b) and phage P335 DNA replication was followed during the infection of L. lactis F4/2 (c) and SMQ-463 (d). Samples $(1 \mathrm{ml})$ of infected cultures $(\mathrm{m} .0 . i .=1)$ were taken every $10 \mathrm{~min}$ and total DNA was isolated from the cellular fraction by the method of Hill et al. (1991). DNA was digested with EcoRV, heat-treated $\left(65^{\circ} \mathrm{C}\right.$ for $\left.10 \mathrm{~min}\right)$ and restriction fragments were separated on a $0.8 \%$ agarose gel. Numbers above the lanes indicate the time of sampling. $\mathrm{C}^{-}$, phage DNA digested with EcoRV; $\mathrm{C}^{+}$, phage DNA digested with EcoRV heated for 10 min at $65^{\circ} \mathrm{C}$; L, $1 \mathrm{~kb}$ DNA ladder $(12 \cdot 2,11 \cdot 2,10 \cdot 2,9 \cdot 2,8 \cdot 1,7 \cdot 1,6 \cdot 1,5 \cdot 0,4 \cdot 1,3 \cdot 1,2 \cdot 0,1 \cdot 6$ and $1 \cdot 0 \mathrm{~kb}$; Gibco-BRL); - , sample taken prior to infection.

\section{Phage P008 and P335 DNA replication assays}

The DNA replication assays of phage ul36 and p2 were done on distinct lactococcal hosts. To confirm that the observed differences were not due to host factors, DNA replication was temporally monitored for the type phages P008 (936 species) and P335 (P335 species), which are lytic for the same host. The e.o.p. of phage P008 and phage P335 on L. lactis F4/2 carrying AbiK (pSRQ817) were $10^{-4}$ and $10^{-5}$, respectively. As observed for $\mathrm{p} 2$, phage P008 DNA was rapidly replicated in sensitive cells and the amount of DNA decreased after 40 min due to cell lysis (Fig. 2a). The two genomic forms of phage DNA were also detected. The immature form was associated with the presence of a $5 \mathrm{~kb} E c o R V$ fragment containing the covalently closed cos sites and the processed form corresponded to the dissociation of this fragment into two smaller fragments. In resistant cells, the processing of the phage DNA to its mature form was severely reduced and no reduction in the amount of DNA was observed at $40 \mathrm{~min}$ (Fig. 2b). For phage P335, the DNA replicative process was observed in the sensitive cells (F4/2) until cell lysis, which occurred $100 \mathrm{~min}$ following infection (Fig. 2c). In the resistant cells, no phage DNA was detected (Fig. 2d). These results are in agreement with the previous study on the effects of AbiK on phage ul36 (Emond et al., 1997). DNA replication experiments using the host strain F4/2 carrying pSRQ830, a pSRQ817 derivative with a frameshift within $a b i K$, ruled out the possibility that the observed molecular consequences could result from the expression of a different gene product from pSRQ817, or even the presence of a site on pSRQ817 that could interact with some phage protein (data not shown).

\section{Monitoring of the lytic cycle by electron microscopy}

Sensitive and resistant cells were infected with phage $\mathrm{p} 2$ and samples were collected at intervals to observe the 

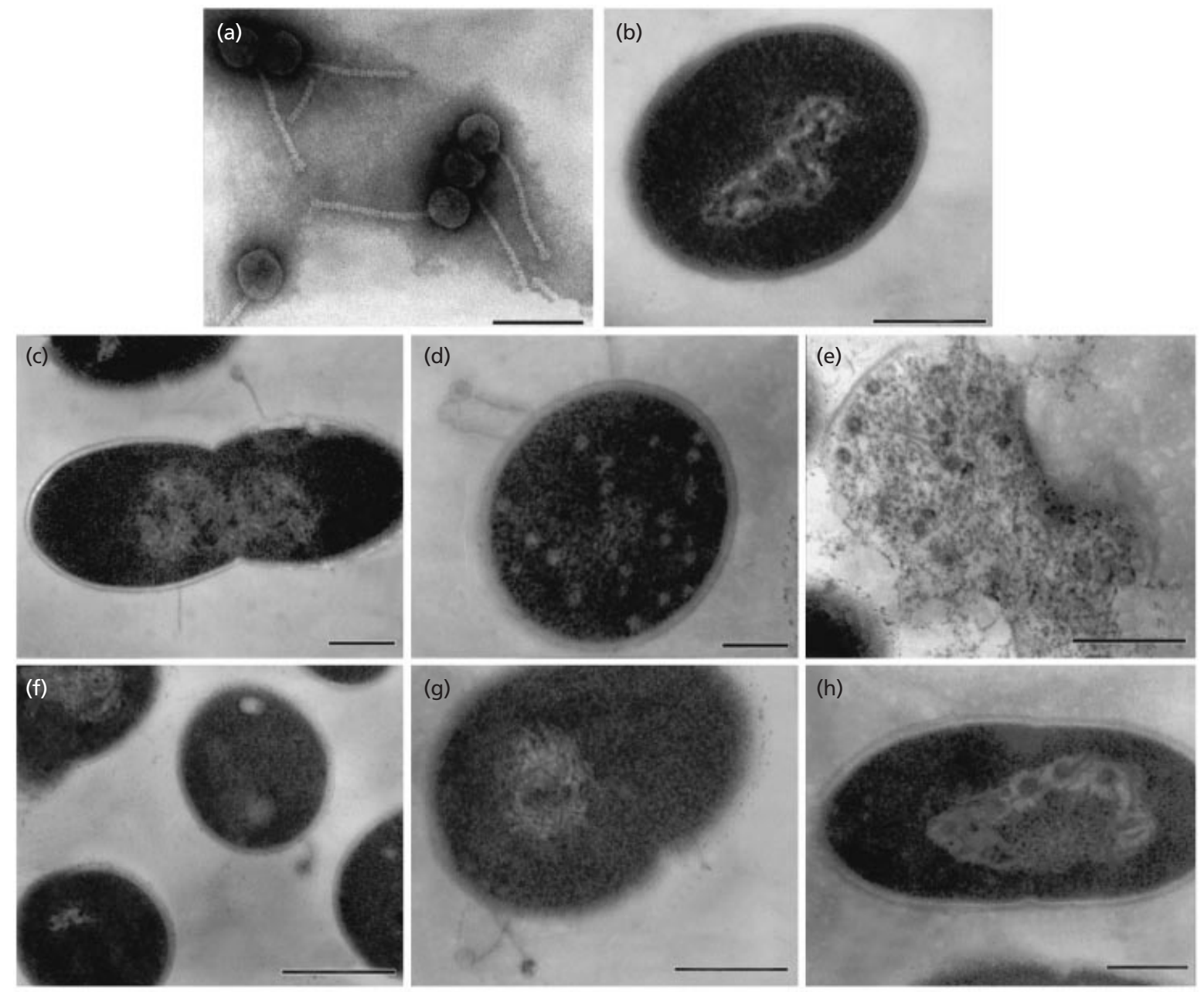

Fig. 3. Monitoring of the lytic cycle by electron microscopy. (a) Phage p2; (b) uninfected L. lactis SMQ-16; (c, d, e) L. lactis SMQ-16 infected with phage p2 at 30,50 and 70 min, respectively; $(f, g, h) L$. lactis SMQ-38 infected with phage p2 at 30 , 50 and $70 \mathrm{~min}$, respectively. Bars: (a) $100 \mathrm{~nm}$; (b-h) $250 \mathrm{~nm}$.

intracellular course of the lytic cycle by electron microscopy (Fig. 3). At 30 min post-infection, most sensitive cells had phages adsorbed to their surface (Fig. 3c). A network of DNA filled a large part of the intracellular space (Fig. 3c). At $50 \mathrm{~min}$, capsid-like structures were detected throughout the cytoplasm and the DNA network was no longer visible, an indication of the packaging process (Fig. 3d). Finally, the infected cells lysed and released headful progeny phages (Fig. 3e). In the $\mathrm{AbiK}^{+}$strain, no such progression of the lytic cycle was observed (Fig. 3f, g and h). Phages adsorbed to the bacterial surface and the presence of empty heads indicated that DNA had entered the cells. No capsid structures were detected within the cytoplasm. However at later stages, a few head-like structures were observed around a DNA network, which is likely to comprise the accumulated phage DNA concatemers evidenced in the DNA replication assays. No cell lysis was noticed at any time in the $\mathrm{AbiK}^{+}$cells.

\section{Effects of m.o.i. on e.c.o.i.}

Studies on phage-host interactions in cells harbouring anti-phage mechanisms are generally performed using non-standardized m.o.i.s. Since discrepancies could result from the use of various m.o.i.s, we measured their impact, ranging from $0 \cdot 1$ to 50 , on the e.c.o.i. of cells carrying AbiK (Fig. 4). For m.o.i.s lower than 5, the e.c.o.i. remained constant, with around $5 \%$ of infected cells releasing progeny phages. Above a m.o.i. of 5, the e.c.o.i. values increased gradually with increasing m.o.i.s. Thus, a relationship exists between the e.c.o.i. and the m.o.i. in a L. lactis strain carrying AbiK.

\section{DISCUSSION}

Although several lactococcal Abi systems have been shown to be efficient on multiple phage species, mechanistic studies are generally conducted on a single species. Here, we showed that even if the resistance 


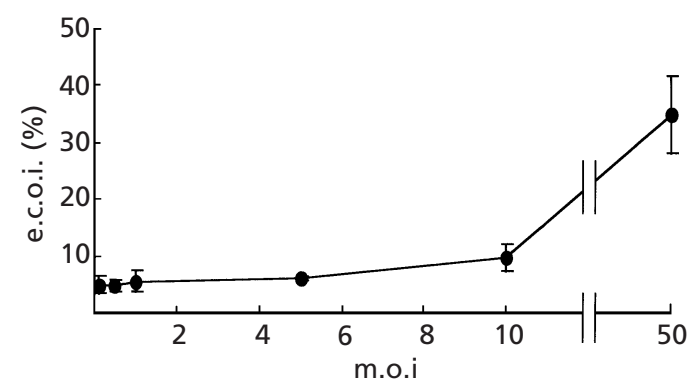

Fig. 4. Effect of the m.o.i. on the e.c.o.i. Cultures of L. lactis SMQ-16 and SMQ-38 were infected with phage p2 at various m.o.i.s. The phages were allowed to adsorb to the cells for $5 \mathrm{~min}$. The cells were then washed twice to remove unadsorbed phages, resuspended in GM17 and plated on the sensitive strain SMQ-16 to count the c.o.i. formed. Error bars indicate the standard deviation of three trials.

mediated by $\mathrm{AbiK}$ on the phage $\mathrm{p} 2$ is relatively similar to that reported for the phage ul36 (Emond et al., 1997), the molecular impacts are clearly distinct. Moreover, the fact that the same differences were observed with phages P008 and P335 replicating on a single host demonstrates that the molecular impacts are related to the particularities of the two phage species, rather than on host factors.

The absence of accumulation of P335 phage DNA in infected cells suggests an interference of $\mathrm{AbiK}$ with an early stage of the lytic cycle. The fact that the concatenated DNA of 936 phages was not efficiently processed into mature genome suggests that AbiK halted the packaging process, possibly as a consequence of the disrupted early stages. These molecular consequences are likely to result from an interaction of AbiK with analogous phage components of both species, or with a host product necessary for a common early step of phage development. A better understanding of the molecular interactions between AbiK and phages of the 936 and P335 species will provide valuable information on the similarities and differences in the lytic cycle of these phages. The absence of the mature processed form of the 936 phage genome in the $\mathrm{AbiK}^{+}$cells could also be the result of defective concatemeric DNA intermediates that cannot serve as a substrate for the synthesis of mature phage DNA, as observed in the case of choleraphage $\phi 149$ infecting Vibrio cholerae biotype El Tor (Chowdhury et al., 1989). However, in that case, the concatemeric DNA formed during the infection was unstable and rapidly degraded (Majumdar et al., 1988).

A direct interference of AbiK with the head morphogenetic pathway of 936 phages cannot be excluded. In phage lambda, mutations affecting late genes involved in head morphogenesis can provoke similar accumulation of concatenated DNA (Catalano et al., 1995; Murialdo, 1991; Murialdo \& Becker, 1978; Murialdo \& Tzamtzis, 1997). Recently, a similar organization of the late genes was observed between lambda and the lactococcal phage sk1, a close relative of P008 and p2 (Chandry et al.,
1997). This finding suggests that the mechanism of action of AbiK on 936 and P335 phages is likely to be different. The large size of the abiK gene (1789 bp) supports the possibility of a multifunctional protein with more than one active site. In Escherichia coli, a high proportion of proteins of more than 300 amino acids are estimated to be multifunctional (Gething, 1997).

We previously demonstrated that the impact of AbiK on phage resistance was substantially improved when cloned in a high-copy vector (Émond et al., 1997). Furthermore, the infection of an $\mathrm{AbiK}^{+}$cell with multiple phages reduced the efficacy of this anti-phage system (data not shown). Therefore, it appears that the balance between the number of invading phages and the intracellular concentration of AbiK molecules is an important variable in experimental procedures on phage-host interactions. Our results showed that AbiK is potent enough to resist multiple phage infections, up to a threshold value, above which the resistance factor is most likely outnumbered and the proportion of viruses escaping $\mathrm{AbiK}$ is enhanced. Similarly, the codominance of phages $\mathrm{p} 2$ and $\mathrm{p} 2 \mathrm{~K}$ in the coinfection experiment supports the idea that competition occurs at the molecular level for factors needed for the AbiK phenotype.

In conclusion, $\mathrm{AbiK}$ has diverse consequences on the lytic cycle of 936 and P335 phages. This is the first report of such a dual effect of an Abi on two phage species. The molecular basis for the different kinds of interactions is not yet understood but further characterization of variant phages resistant to $\mathrm{AbiK}$, such as $\mathrm{p} 2 \mathrm{~K}$, could be a useful tool in investigating the AbiK mode of action. However, our results emphasize the importance of conducting mechanistic studies on both phage species. Finally, the determination of e.c.o.i. with extended m.o.i. values could represent an additional tool to evaluate the robustness of any given Abi system.

\section{ACKNOWLEDGEMENTS}

We are grateful to $\mathrm{H}$. Deveau for screening L. lactis strains for sensitivity to 936 and P335 phages. We thank T. R. Klaenhammer for phage P335, and H. W. Ackermann for phage P008 and L. lactis strain F4/2. We also thank J. Bouchard for inspiring discussion. This study was supported in part by Quest International and by a strategic grant from the Natural Sciences and Engineering Research Council of Canada.

\section{REFERENCES}

Allison, G. E. \& Klaenhammer, T. R. (1998). Phage resistance mechanisms in lactic acid bacteria. Int Dairy J 8, 207-226.

Anba, J., Bidnenko, E., Hillier, A., Ehrlich, S. D. \& Chopin, M. C. (1995). Characterization of the lactococcal abiD1 gene coding for phage abortive infection. J Bacteriol 177, 3818-3823.

Bidnenko, E., Ehrlich, S. D. \& Chopin, M. C. (1995). Phage operon involved in sensitivity to the Lactococcus lactis abortive infection mechanism AbiD1. J Bacteriol 177, 3824-3829.

Catalano, C. E., Cue, D. \& Feiss, M. (1995). Virus DNA packaging: the strategy used by phage lambda. Mol Microbiol 16, 1075-1086.

Chandry, P. S., Moore, S. C., Boyce, J. D., Davidson, B. E. \& Hillier, 
A. J. (1997). Analysis of the DNA sequence, gene expression, origin of replication and modular structure of the Lactococcus lactis lytic bacteriophage sk1. Mol Microbiol 26, 49-64.

Chibani Azaïez, S. R., Fliss, I., Simard, R. E. \& Moineau, S. (1998). Monoclonal antibodies raised against native major capsid proteins of lactococcal c2-like bacteriophages. Appl Environ Microbiol 64, 4255-4259.

Chowdhury, R., Biswas, S. K. \& Das, J. (1989). Abortive replication of choleraphage $\phi 149$ in Vibrio cholerae biotype El Tor. J Virol 63, 392-397.

Cluzel, P.-J., Chopin, A., Ehrlich, S. D. \& Chopin, M. C. (1991). Phage abortive infection mechanism from Lactococcus lactis subsp. lactis, expression of which is mediated by an Iso-ISS1 element. Appl Environ Microbiol 57, 3547-3551.

Deng, Y. M., Harvey, M. L., Liu, C. Q. \& Dunn, N. W. (1997). A novel, plasmid-encoded phage abortive infection system from Lactococcus lactis biovar diacetylactis. FEMS Microbiol Lett $\mathbf{1 4 6}$, 149-154.

Deng, Y. M., Liu, C. Q. \& Dunn, N. W. (1999). Genetic organization and functional analysis of a novel phage abortive infection system, AbiL, from Lactococcus lactis. J Biotechnol 67, 135-149.

Dinsmore, P. K. \& Klaenhammer, T. R. (1995). Bacteriophage resistance in Lactococcus. Mol Biotechnol 4, 297-314.

Dinsmore, P. K. \& Klaenhammer, T. R. (1997). Molecular characterization of a genomic region in a Lactococcus bacteriophage that is involved in its sensitivity to the phage defense mechanism AbiA. J Bacteriol 179, 2949-2957.

Dinsmore, P. K., O'Sullivan, D. J. \& Klaenhammer, T. R. (1998). A leucine repeat motif in AbiA is required for resistance of Lactococcus lactis to phages representing three species. Gene 212, 5-11.

Durmaz, E., Higgins, D. L. \& Klaenhammer, T. R. (1992). Molecular characterization of a second abortive phage resistance mechanism in Lactococcus lactis subsp. lactis ME2. J Bacteriol 174, 7463-7469.

Émond, É., Holler, B. J., Boucher, I., Vandenbergh, P. A., Vedamuthu, E. R., Kondo, J. K. \& Moineau, S. (1997). Phenotypic and genetic characterization of the bacteriophage abortive infection mechanism AbiK from Lactococcus lactis. Appl Environ Microbiol 63, 1274-1283.

Émond, É., Dion, É., Walker, S. A., Vedamuthu, E. R., Kondo, J. K. \& Moineau, S. (1998). AbiQ, an abortive infection mechanism from Lactococcus lactis. Appl Environ Microbiol 64, 4748-4756.

Garvey, P., Fitzgerald, G. F. \& Hill, C. (1995). Cloning and DNA sequence analysis of two abortive infection phage resistance determinants from the lactococcal plasmid pNP40. Appl Environ Microbiol 61, 4321-4328.

Geis, A., Janzen, T., Teuber, M. \& Wirsching, F. (1992). Mechanism of plasmid mediated bacteriophage resistance in lactococci. FEMS Microbiol Lett 94, 7-14.

Gething, M. J. (1997). Protein folding. The difference with prokaryotes. Nature 388, 329.

Hill, C., Miller, L. A. \& Klaenhammer, T. R. (1990). Nucleotide sequence and distribution of the pTR2030 resistance determinant (hsp) which aborts bacteriophage infection in lactococci. Appl Environ Microbiol 56, 2255-2258.

Hill, C., Massey, I. J. \& Klaenhammer, T. R. (1991). Rapid method to characterize lactococcal bacteriophage genomes. Appl Environ Microbiol 57, 283-288.

Jarvis, A. W. (1978). Serological studies of a host range mutant of a lactic streptococcal bacteriophage. Appl Environ Microbiol 36, 785-789.
Jarvis, A. W., Fitzgerald, G. F., Mata, M., Mercenier, A., Neve, H., Powell, I., Ronda, C., Saxelin, M. \& Teuber, M. (1991). Species and type phages of lactococcal bacteriophages. Intervirology 32, 2-9.

Klaenhammer, T. R. (1989). Genetic characterization of multiple mechanisms of phage defense from a prototype phage-insensitive strain, Lactococcus lactis ME2. J Dairy Sci 72, 3429-3443.

Klaenhammer, T. R. \& Sanozky, R. B. (1985). Conjugal transfer from Streptococcus lactis ME2 of plasmids encoding phage resistance, nisin resistance and lactose-fermenting ability: evidence for a high-frequency conjugative plasmid responsible for abortive infection of virulent bacteriophage. J Gen Microbiol 131, 1531-1541.

McKay, L. L., Baldwin, K. A. \& Zottola, E. A. (1972). Loss of lactose metabolism in lactic streptococci. Appl Environ Microbiol 23, 1090-1096.

McLandsborough, L. A., Kolaetis, K. M., Requena, T. \& McKay, L. L. (1995). Cloning and characterization of the abortive infection genetic determinant AbiD isolated from pBF61 of Lactococcus lactis subsp. lactis KR5. Appl Environ Microbiol 61, 2023-2026.

Majumdar, S., Dey, S. N., Chowdhury, R., Dutta, C. \& Das, J. (1988). Intracellular development of choleraphage $\phi 149$ under permissive and nonpermissive conditions: an electron microscopic study. Intervirology 29, 27-38.

Moineau, S., Fortier, J., Ackermann, H. W. \& Pandian, S. (1992). Characterization of lactococcal bacteriophages from Québec cheese plants. Can J Microbiol 38, 875-882.

Moineau, S., Durmaz, E., Pandian, S. \& Klaenhammer, T. R. (1993). Differentiation of two abortive mechanisms by using monoclonal antibodies directed toward lactococcal bacteriophage capsid proteins. Appl Environ Microbiol 59, 208-212.

Moineau, S., Pandian, S. \& Klaenhammer, T. R. (1994). Evolution of a lytic bacteriophage via DNA acquisition from the Lactococcus lactis chromosome. Appl Environ Microbiol 60, 1832-1841.

Moineau, S., Walker, S. A., Vedamuthu, E. R. \& Vandenbergh, P. A. (1995). Cloning and sequencing of $L l a \mathrm{DCHI}$ restriction and modification genes from Lactococcus lactis and relatedness of this system to the Streptococcus pneumoniae DpnII system. Appl Environ Microbiol 61, 2193-2202.

Moineau, S., Borkaev, M., Holler, B. J., Walker, S. A., Kondo, J. K., Vedamuthu, E. R. \& Vandenbergh, P. A. (1996). Isolation and characterization of lactococcal bacteriophages from cultured buttermilk plants in the United States. J Dairy Sci 79, 2104-2111. Murialdo, H. (1991). Bacteriophage lambda DNA maturation and packaging. Annu Rev Biochem 60, 125-153.

Murialdo, H. \& Becker, A. (1978). Head morphogenesis of complex double-stranded deoxyribonucleic acid bacteriophages. Microbiol Rev 42, 529-576.

Murialdo, H. \& Tzamtzis, D. (1997). Mutations of the coat protein gene of bacteriophage lambda that overcome the necessity for the FI gene; the EFi domain. Mol Microbiol 24, 341-353.

O'Connor, L., Coffey, A., Daly, C. \& Fitzgerald, G. F. (1996). AbiG, a genotypically novel abortive infection mechanism encoded by plasmid pCI750 of Lactococcus lactis subsp. cremoris UC653. Appl Environ Microbiol 62, 3075-3082.

Parreira, R., Ehrlich, S. D. \& Chopin, M. C. (1996). Dramatic decay of the phage transcripts in lactococcal cells carrying the abortive infection determinant AbiB. Mol Microbiol 19, 221-230.

Prévots, F. \& Ritzenthaler, P. (1998). Complete sequence of the new lactococcal abortive phage resistance gene abiO. J Dairy Sci 81, 1483-1485.

Prévots, F., Daloyau, M., Bonin, O., Dumont, X. \& Tolou, S. (1996). 
Cloning and sequencing of the novel abortive infection gene abiH of Lactococcus lactis ssp. lactis biovar diacetylactis S94. FEMS Microbiol Lett 142, 295-299.

Prévots, F., Tolou, S., Delpech, B., Kaghad, M. \& Daloyau, M. (1998). Nucleotide sequence and analysis of the new chromosomal abortive gene abiN of Lactococcus lactis subsp. cremoris S114. FEMS Microbiol Lett 159, 331-336.

Pringle, C. R. (1996). Virus taxonomy 1996 - a bulletin from the Xth International Congress of Virology in Jerusalem. Arch Virol 141, 2251-2256.

Sambrook, J., Fritsch, E. F. \& Maniatis, T. (1989). Molecular Cloning: a Laboratory Manual, 2nd edn. Cold Spring Harbor, NY: Cold Spring Harbor Laboratory.

Sanders, M. E. \& Klaenhammer, T. R. (1980). Restriction/ modification in group $\mathrm{N}$ streptococci: effect of heat on development of modified lytic bacteriophage. Appl Environ Microbiol 40, 500-506.
Sing, W. D. \& Klaenhammer, T. R. (1990). Plasmid-induced abortive infection in Lactococci: a review. J Dairy Sci 73, 2239-2251.

Southern, E. M. (1975). Detection of specific sequences among DNA fragments separated by gel electrophoresis. J Mol Biol 98, 503-517.

Strausbauch, P., Roberson, L. \& Sehgal, N. (1985). Embedding of cell suspensions in ultra-low gelling temperature agarose: improved specimen preparation for TEM. J Electron Microsc Tech 2, 261-262.

Su, P., Harvey, M., Im, H. J. \& Dunn, N. W. (1997). Isolation, cloning and characterization of the abil gene from Lactococcus lactis subsp. lactis M138 encoding abortive phage infection. J Biotechnol 54, 95-104.

Received 18 May 1999; revised 14 September 1999; accepted 22 October 1999. 